\title{
RESEARCH ON ATHLETES' PSYCHOLOGICAL \\ REGULATION ABILITY BASED ON BACK PROPAGATION (BP) NEURAL NETWORK ALGORITHM
}

\author{
INVESTIGAÇÃO SOBRE A HABILIDADE DE CONTROLE PSICOLÓGICO DE ATLETAS COM BASENO \\ ALGORITMO DEREDE NEURAL BACKPROPAGATION \\ INVESTIGACIÓN SOBRE LA CAPACIDAD DE AJUSTEPSICOLÓGICO DE LOS ATLETAS BASADA EN EL \\ ALGORITMO DERED NEURONAL BP
}

\section{Yun $\operatorname{Tan}^{1}$ (D) \\ (Public Health Education) \\ Guoqing Zhang² (D) \\ (Public Sports)}

1. Physical Education School, Southwest University, Chongqing, 400715, China.

2. Chong Qing Electric Power college, Chongqing, 400053, China.

\section{Correspondence:}

Chongqing, 400715, China. gabyb2516pdat55@126.com.

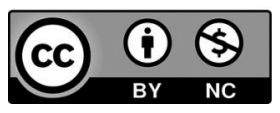

\begin{abstract}
Athletes' psychological control ability directly affects competitions. Therefore, it is necessary to supervise the athletes' game psychology. Athletes' game state supervision model is constructed through the facial information extraction algorithm. The homography matrix and the calculation method are introduced. Then, two methods are introduced to solve the rotation matrix from the homography matrix. After the rotation matrix is solved, the method of obtaining the facial rotation angle from the rotation matrix is introduced. The two methods are compared in the simulation data, and the advantages and disadvantages of each algorithm are analyzed to determine the method used in this paper. The experimental results show that the model prediction accuracy reaches $70 \%$, which can effectively supervise the psychological state of athletes. This research study is of great significance to improve the performance of athletes in competitions and improve the application of back propagation (BP) neural network algorithm.
\end{abstract}

Keywords: Neural Networks, Computer; Athletes; Handling, Psychological.

\section{RESUMO}

A capacidade de controle psicológico de atletas afeta diretamente as competições. Portanto, é muito necessário supervisionar a psicologia de jogo desses indivíduos. O modelo de supervisão do estado de jogo dos atletas é construído através do algoritmo de extração de informações faciais. A matriz de homografia e o método de cálculo são introduzido. Em seguida, são introduzidos dois métodos para resolver a matriz de rotação a partir da matriz de homografia. Após a resolução da matriz de rotação, introduz-se o método de obtenção do ângulo de rotação facial a partir dessa matriz. Os dois métodos são comparados nos dados da simulação, e as vantagens e desvantagens de cada algoritmo são analisadas para determinar o método utilizado neste estudo. Os resultados experimentais mostram que a precisão da previsão do modelo atinge 70\%, sendo possivel efetivamente supervisionar o estado psicológico dos atletas. O presente estudo é de grande importância para melhorar o desempenho dos atletas em competições e melhorar a aplicação do algoritmo de rede neural backpropagation (BP).

Descritores: Redes Neurais de Computação; atletas; Manobra Psicológica.

\section{RESUMEN}

La capacidad de control psicológico de atletas afecta directamente las competencias. Por lo tanto, es muy necesario supervisar la psicología de juego de esos individuos. El modelo de supervisión del estado de juego de los atletas es construido por medio del algoritmo de extracción de informaciones faciales. La matriz de homografía yel método de cálculo son introducidos. Enseguida, son introducidos dos métodos para resolver la matriz de rotación a partir de la matriz de homografía. Después de la resolución de la matriz de rotación, se introduce el método de obtención del ángulo de rotación facial a partir de esa matriz. Los dos métodos son comparados en los datos de la simulación, y las ventajas y desventajas de cada algoritmo son analizadas para determinar el método utilizado en este estudio. Los resultados experimentales muestran que la precisión de la previsión del modelo alcanza 70\%, siendo posible efectivamente supervisar el estado psicológico de los atletas. El presente estudio es de gran importancia para mejorar el desempeño de los atletas en competencias y mejorar la aplicación del algoritmo de red neuronal backpropagation (BP).

Descriptores: Redes Neuronales de Computación; Atletas; Maniobra Psicológica 


\section{INTRODUCTION}

For athletes, their psychological state during the game will have a direct impact on the performance. ' Only by improving the athlete's ability to control the game can the athletes play a stable role in the competition, and it is necessary to improve the athlete's psychological control ability and appropriate supervision of the athlete's psychological and sports status. ${ }^{2}$ On this basis, the BP neural network algorithm is used to study the athlete's game state, and the athlete's game state supervision system is constructed in order to promote the improvement of athletes' psychological control ability.

For the research method, combining the homography matrix relationship between planar image projections, the algorithm of obtaining facial rotation angle from homography matrix is studied. In this research, the homography matrix decomposition algorithm and the equivalent algorithm are analyzed. The performance of the two algorithms under different errors is studied in detail through simulation experiments and the performance of the two algorithms is analyzed comprehensively. At last, the homography matrix equivalent algorithm with simpler derivation process and better error robustness is selected.

\section{RELATED WORK}

So far, the research on the abnormal state monitoring methods of athletes all over the world has had relatively good research results. Song FY, aiming at abnormal movements such as fatigue exercise, distraction, drink movement and emotional stress, proposed corresponding detection and supervision methods. ${ }^{3}$ Percentage of eyelid closure over the pupil over time (PERCLOS) was used as a measure of fatigue by Liu $\mathrm{T}$, which is considered to be one of the most promising methods for detecting fatigue motion. ${ }^{4}$ A variety of measurements are used to study athletes' motor behavior problems by the detection system developed by Colzato LS. ${ }^{5}$ In Masaki H's research, they accurately measured head movements, pupil diameter changes, and blink frequency through dedicated cameras, electroencephalographs, etc, of which the results showed that when people's eyes closed between 0.2 seconds and 0.3 seconds, the exercise is safe. ${ }^{6}$ The problem of distraction has become the main direction of research. Przednowek K, who began to study the influence of motion video on exercise and achieved important results, proposed that the sway of the wiper has a hypnotic effect on athletes.?

\section{BP NEURAL NETWORK BASED ATHLETES' PSYCHOLOGICAL STATE SUPERVISION MODEL}

\section{Athletes' Psychological State Supervision Algorithm}

The Haar feature, also known as the Haar-like feature, is a feature of grayscale variation in the reaction region, including four forms, namely edge features, linear features, center features, and diagonal features. According to these four basic characteristics, it can be combined into various complex feature templates. Each feature template has its calculated specific value, and the Eigen-value of the Haar feature is the sum of the luminance values of all the pixels in the white area of the template minus the sum of the luminance values of all the pixels in the black area in the template. The Haar feature essentially reflects the trend of the gray value in the region. The core of the Haar feature is to represent the current image feature using the difference between the sum of the gray values of the pixels in the black and white region. Because the calculation of Haar feature takes into account the difference of gray value in the region, it is suitable for some detection with obvious change of gray value. For example, in face detection, the face can be effectively detected by Haar feature, because the gray value of eyes, nose and mouth in face is obviously different from that in other regions.
So Haar feature is very suitable for face detection. Figure 1 shows the corresponding Haar features in several forms.

Regardless of how the Haar feature changes, the calculation of its Eigen-values is similar. For the two characteristics of A and D in Figure 2, the Eigen-value calculation formula of Haar feature is: $v=S u m$ white-Sum black; for $B$ and $C$, it should be ensured that the black and white pixel frames are set to be the same size, that is, for $B, v=S m n$ white-2*Sum black, the black pixel should also be multiplied by a considerable factor when calculating the Eigen-value in $\mathrm{C}$ to ensure that the total number of pixels in the black and white regions is the same. The four forms of Haar features are also called feature prototypes. According to these four feature prototypes, a variety of feature templates can be combined. By changing the length and width of the prototype and the position in the image, many Haar features can also be listed in one image. These Haar features have their achievable Eigen-values. Since the coordinates and sizes of these templates of Haar feature can be adjusted at will, the calculation of Haar feature is very large for an image, such as the number of features in an image of $24^{*} 24$ pixels is even more than 160,000 . With such a large amount of computation, it is necessary to use appropriate algorithms to calculate Haar features. As a practical means to solve the problem of Haar feature calculation, integral graph makes the application of Haar feature more extensive. The idea of integral graph is to calculate the sum of the brightness values of the pixels in the region surrounded by any point in the image and the starting point of the image. The calculation of Haar features seems to be simply the addition and subtraction of luminance values in two or several regions. The integral graph can effectively reduce the computational complexity. After the integral graph is created, the sum of gray values of each image block pixel can be completed by four-step addition and subtraction as shown in Figure 2.

Set the four vertices of D as a, p, Y, and 8, respectively, and the pixel sum of $D$ can be expressed as shown in equation (1).

$$
D_{\text {sum }}=i(\alpha)+i(\beta)-i(\gamma)+i(\delta)
$$

The Eigen value of the Haar feature is the difference between the sum of the gray values in the two regions, so it can be conveniently calculated using the integral graph. The pixel sum of each region is calculated by using equation (1), and then the difference is obtained to obtain the Eigen-value of the corresponding Haar feature. The sum of each block is only related to the values of the four corner points in the integral map. Therefore, even if there is a change in the scale, the time consumed by the algorithm is constant when calculating the Haar feature. By constructing an integral map of the image in this way, it is convenient to calculate the values of all Haar features. The basic form of Hal characteristics is shown in Figure 1. The application of integral graph greatly improves the calculation speed and detection speed of Haar features, which lays a solid foundation for the wide application of Haar features. For the detection of human face, firstly, a large number of face

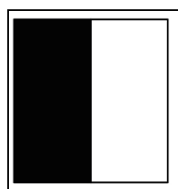

A

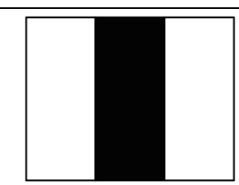

B

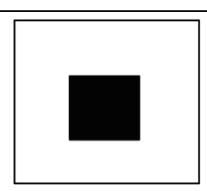

C

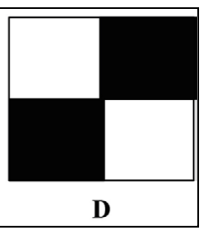

D
Figure 1. The Basic Form of Haar Characteristic.

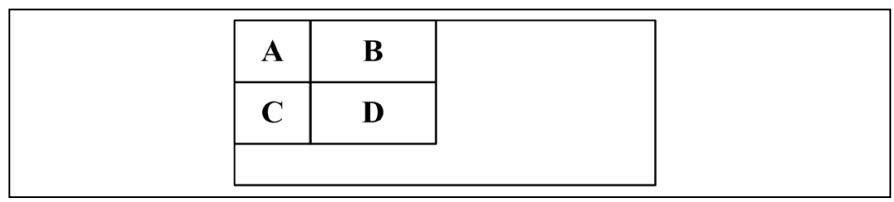

Figure 2. Integral Diagram Partition Diagram. 
images with different expressions, skin color, appearance, and illumination intensity are collected, and the cropping is scaled to the same size. In this paper, a picture with a size of $24^{*} 24$ pixels is used. The positive samples trained in this paper are shown in Figure 3, 1,500 samples in total. Then collect as many images as possible without human face (3000 in total at last) and scale to the same size as a negative sample. Write the training program for the classifier in $\mathrm{C}++$. The program for training the classifier consists of two parts, from which the characteristics of all pictures are calculated and saved. The number of positive and negative samples is counted, the Haar features of all training images are calculated, and the features are written to the file; the Adaboost algorithm is run to train the classifier. Adaboost initialization, respectively reads the Haar Eigen-values of the positive and negative samples in the face training image. Train the Adaboost classifier, set the number of trainings, and in each training period: iterate the weights to find the optimal classifier. Save the training results in a file. After the training is completed, a file with the format xml is obtained, which is the trained classifier and is applied to detect faces.

\section{EXPERIMENTAL DESIGN AND ANALYSIS}

\section{Experimental Methods}

To better study the effects of the two algorithms, it is convenient to control the error of the input data, so that the performance of the algorithm can be compared and analyzed more directly, and the simulation experiment is firstly used to verify in this thesis. According to the calibrated camera internal parameters, four sets of data points $A(5,5,20), B(3,-5,20)$, $C(-5,5,20), D(-3,-5,20)$ are simulated in the position facing the camera. As shown in Figure 7. It's facing the camera, so the camera parameter $\mathrm{R}$ $=\mathrm{I}, \mathrm{T}=0$. According to the conversion relationship between the pixel coordinate system and the world coordinate system, referring to formulas (2-4), (2-5), set the image size $640 * 480$. The image coordinates of the four points can be obtained as follows: a $(479.45,398.28)$, B $(415.67,81.725), C$
$(160.55,398.28), \mathrm{D}(224.33,81.725)$. The plane is rotated 60 degrees counter-clockwise around the longitudinal axis shown in Fig. 7, and the image coordinates after rotation are A1 $(421.76,442.01), \mathrm{B} 1(374.98,58.095), \mathrm{C} 1$ (254.46, 370.11), D1 (277.66, 99.922), as shown in Figure 4.

\section{Analysis of Experimental Results}

In the experiment, the angle solution of the plane rotated around $x$-axis and $z$-axis is verified. The simulation results show that the algorithm can get the planar rotation pin, and add errors to the simulation data to verify the robustness of the algorithm. Firstly, the same error error1 is added to the corresponding points after four groups of rotation to simulate the detection error. When the error is between $[-10,10]$, the calculated rotation angle is shown in Table 1.

Errors are added to the simulation data to verify the robustness of the algorithm. Firstly, the same error is added to the corresponding points after four groups of rotation to simulate the detection error. When the error is between $[-10,10]$, the calculated rotation angle is shown in Table 1.

\section{CONCLUSION}

Based on the BP neural network algorithm, the athletes' psychological control ability is studied; in addition, the algorithm of obtaining the athlete's facial corner from the plane image is studied as well. Using the homography matrix existing in the imaging process of planar objects, the four feature points of the human face are regarded as one plane, and then the rotation matrix is calculated to determine the facial turn of the athlete. In the solution of the rotation matrix, the homography matrix decomposition algorithm and the homography matrix equivalent algorithm are analyzed, and the simulation experiment is used to test. The advantages and disadvantages of the two algorithms are accurately analyzed, and then the homography matrix equivalent algorithm which is more suitable for this paper is selected. After obtaining the facial

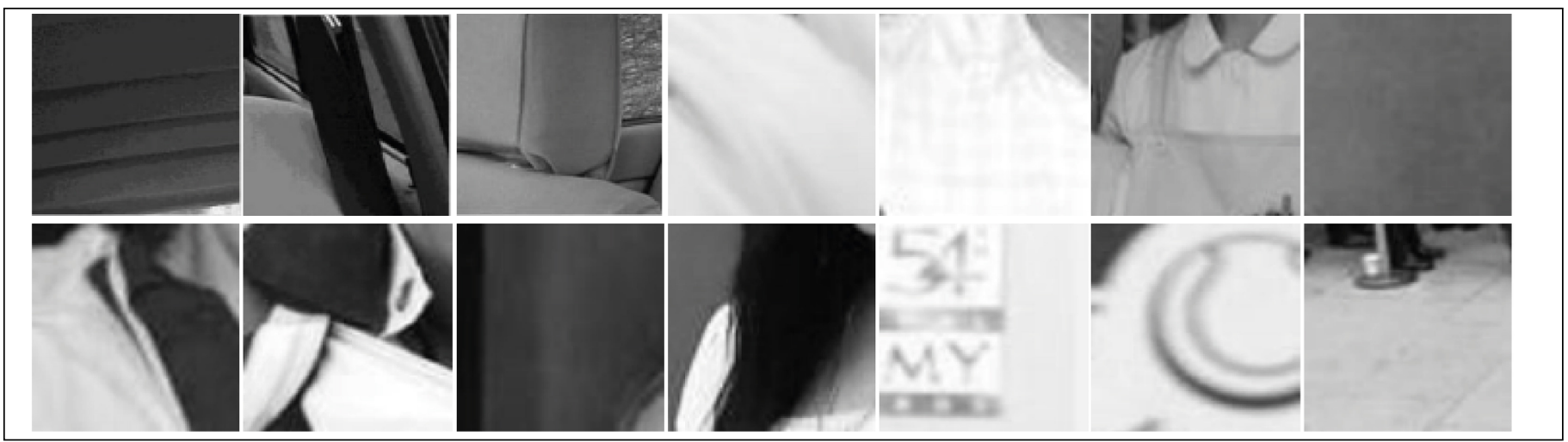

Figure 3. Partial negative sample legend.
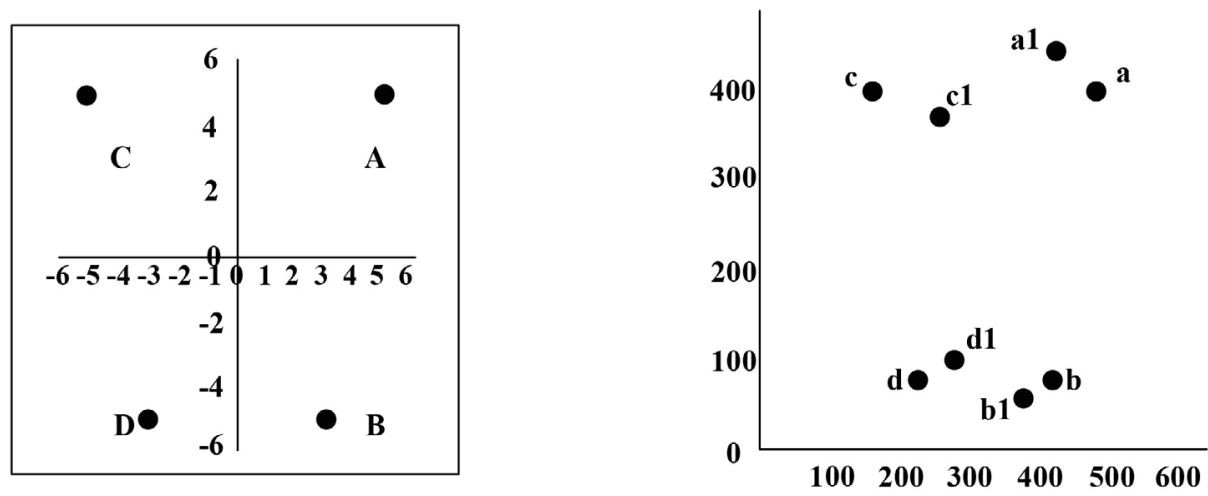

Figure 4. Analog data schematic. 
Table 1. One-Dimensional Error Results of Homography Matrix Decomposition Algorithms.

\begin{tabular}{c|c|c|c}
\hline Error/pixel & $\begin{array}{c}\text { Rotation angle/ } \\
\text { degree around } \mathbf{x}\end{array}$ & $\begin{array}{c}\text { Rotation angle/ } \\
\text { degree around } \mathbf{y}\end{array}$ & $\begin{array}{c}\text { Rotation angle/ } \\
\text { degree around } \mathbf{z}\end{array}$ \\
\hline-10 & $-1.93253 \mathrm{e}-005$ & -59.5579 & $1.6835 \mathrm{e}-005$ \\
\hline-9 & $-1.93074 \mathrm{e}-005$ & -59.6015 & $1.68824 \mathrm{e}-005$ \\
\hline-8 & $-1.92897 \mathrm{e}-005$ & -59.6452 & $1.69301 \mathrm{e}-005$ \\
\hline-7 & $-1.9272 \mathrm{e}-005$ & -59.6891 & $1.69778 \mathrm{e}-005$ \\
\hline-6 & $-1.92546 \mathrm{e}-005$ & -59.7331 & $1.70258 \mathrm{e}-005$ \\
\hline-5 & $-2.01166 \mathrm{e}-005$ & -59.7772 & $1.70721 \mathrm{e}-005$ \\
\hline-4 & $-1.97469 \mathrm{e}-005$ & -59.8215 & $1.71213 \mathrm{e}-005$ \\
\hline-3 & $-1.97291 \mathrm{e}-005$ & -59.8659 & $1.71699 \mathrm{e}-005$ \\
\hline-2 & $-1.97115 \mathrm{e}-005$ & -59.9105 & $1.72187 \mathrm{e}-005$ \\
\hline-1 & $-2.00438 \mathrm{e}-005$ & -59.9552 & $1.72675 \mathrm{e}-005$ \\
\hline 0 & $-2.0026 \mathrm{e}-005$ & -60 & $1.73167 \mathrm{e}-005$ \\
\hline 1 & $-1.96596 \mathrm{e}-005$ & -60.045 & $1.7366 \mathrm{e}-005$ \\
\hline 2 & $-4.69702 \mathrm{e}-005$ & -60.0901 & $4.03932 \mathrm{e}-005$ \\
\hline 3 & $-4.7078 \mathrm{e}-005$ & -60.1354 & $4.05131 \mathrm{e}-005$ \\
\hline 4 & $-4.69607 \mathrm{e}-005$ & -60.1808 & $4.06331 \mathrm{e}-005$ \\
\hline 5 & $-4.73684 \mathrm{e}-005$ & -60.2264 & $4.07546 \mathrm{e}-005$ \\
\hline 6 & $-4.73264 \mathrm{e}-005$ & -60.2721 & $4.08757 \mathrm{e}-005$ \\
\hline 7 & $-4.78076 \mathrm{e}-005$ & -60.3179 & $4.09987 \mathrm{e}-005$ \\
\hline 8 & $-4,77656 \mathrm{e}-005$ & -60.3639 & $4.11209 \mathrm{e}-005$ \\
\hline 9 & $-4.7426 \mathrm{e}-005$ & -60.4101 & $4.12425 \mathrm{e}-005$ \\
\hline 10 & $-4.74596 \mathrm{e}-005$ & -60.4563 & $4.13658 \mathrm{e}-005$ \\
\hline & & &
\end{tabular}

Table 2. Four-Dimensional Error Results of Homography Matrix Decomposition Algorithms.

\begin{tabular}{c|c|c|c|c|c|c}
\hline $\begin{array}{c}\text { errorl } \\
\text { /pixel }\end{array}$ & $\begin{array}{c}\text { error2 } \\
\text { /pixel }\end{array}$ & $\begin{array}{c}\text { error3 } \\
\text { /pixel }\end{array}$ & $\begin{array}{c}\text { error4 } \\
\text { /pixel }\end{array}$ & $\begin{array}{c}\text { Rotation } \\
\text { angle/degree } \\
\text { around } \mathbf{x}\end{array}$ & $\begin{array}{c}\text { Rotation } \\
\text { angle/degree } \\
\text { around y }\end{array}$ & $\begin{array}{c}\text { Rotation angle/ } \\
\text { degree around z }\end{array}$ \\
\hline 3 & 0 & -2 & -2 & -1.10769 & -59.5586 & 0.911619 \\
\hline 3 & 0 & -2 & -1 & -3.70887 & -59.6285 & 3.07675 \\
\hline 3 & 0 & -2 & 0 & -6.34434 & -59.6646 & 5.2767 \\
\hline 3 & 0 & -2 & 1 & -9.00645 & -59.6659 & 7.50267 \\
\hline 3 & 0 & -2 & 2 & -11.6871 & -59.6313 & 9.74541 \\
\hline 3 & 0 & -2 & 3 & -4.3781 & -59.5604 & 11.9955 \\
\hline 3 & 0 & -2 & 4 & -17.0712 & -59.4527 & 14.2435 \\
\hline 3 & 0 & -2 & 5 & -19.7582 & -59.3082 & 16.4801 \\
\hline 3 & 0 & -2 & 6 & -22.4314 & -59.127 & 18.6966 \\
\hline 3 & 0 & -2 & 7 & -25.0836 & -58.9096 & 20.8849 \\
\hline
\end{tabular}

corner, the discriminant criterion of distraction is proposed, that is, the single line of sight deviation duration exceeds 2 seconds, or within 10 seconds, the proportion of the athlete facing the front is less than $70 \%$, which is judged to be distracting. The simulation experiment is carried out based on VS2015 and OpenCV3.4. Experiments indicate that the face detection accuracy of the algorithm is about $94 \%$, and the detection accuracy of face feature points is more than $95 \%$. For distracted video, the detection rate is over $90 \%$. At present, there is a big problem in
Table 3. $z=10$ decomposition error

\begin{tabular}{c|c|c|c|c|c|c}
\hline $\begin{array}{c}\text { error2 } \\
\text { /pixel }\end{array}$ & error2 & error3 & error4 & $\begin{array}{c}\text { Rotation } \\
\text { angle/degree } \\
\text { around } \mathbf{p i x e l}\end{array}$ & $\begin{array}{c}\text { Rotation } \\
\text { angle/degree } \\
\text { around y }\end{array}$ & $\begin{array}{c}\text { Rotation angle/ } \\
\text { degree around z }\end{array}$ \\
\hline 3 & 0 & -2 & -2 & -0.034 & -59.78 & 0.0142 \\
\hline 3 & 0 & -2 & -1 & -0.68465 & -59.8272 & 0.495374 \\
\hline 3 & 0 & -2 & 0 & -1.34215 & -59.8794 & 0.982573 \\
\hline 3 & 0 & -2 & 1 & -2.00551 & -59.93 & 1.47584 \\
\hline 3 & 0 & -2 & 2 & -2.67473 & -59.9791 & 1.97516 \\
\hline 3 & 0 & -2 & 3 & -3.3498 & -60.0266 & 2.48051 \\
\hline 3 & 0 & -2 & 4 & -4.0307 & -60.0725 & 2.99188 \\
\hline 3 & 0 & -2 & 5 & -4.71743 & -60.1167 & 3.50923 \\
\hline 3 & 0 & -2 & 6 & -5.40997 & -60.1593 & 4.03253 \\
\hline 3 & 0 & -2 & 7 & -6.10828 & -60.2 & 4.56175 \\
\hline
\end{tabular}

Table 4. $z=5$ decomposition error.

\begin{tabular}{c|c|c|c|c|c|c}
\hline $\begin{array}{c}\text { errorl } \\
\text { /pixel }\end{array}$ & error2 & error3 & error4 \\
/pixel & /pixel & $\begin{array}{c}\text { Rotation } \\
\text { angle/degree } \\
\text { around } \mathbf{x}\end{array}$ & $\begin{array}{c}\text { Rotation } \\
\text { angle/degree } \\
\text { around y }\end{array}$ & $\begin{array}{c}\text { Rotation angle/ } \\
\text { degree around z }\end{array}$ \\
\hline 3 & 0 & -2 & -2 & 0.00566256 & -59.8811 & 0.031321 \\
\hline 3 & 0 & -2 & -1 & -0.0694108 & -59.9137 & -0.002265 \\
\hline 3 & 0 & -2 & 0 & -0.145182 & -59.9462 & -0.035227 \\
\hline 3 & 0 & -2 & 1 & -0.221652 & -59.9786 & -0.067529 \\
\hline 3 & 0 & -2 & 2 & -0.298819 & -60.0109 & -0.099171 \\
\hline 3 & 0 & -2 & 3 & -0.376683 & -60.0431 & -0.130158 \\
\hline 3 & 0 & -2 & 4 & -0.455243 & -60.0752 & -0.160469 \\
\hline 3 & 0 & -2 & 5 & -0.5345 & -60.1073 & -0.190098 \\
\hline 3 & 0 & -2 & 6 & -0.614452 & -60.1392 & -0.219037 \\
\hline 3 & 0 & -2 & 7 & -0.6951 & -60.1711 & -0.247278 \\
\hline
\end{tabular}

athletes' state detection: there is no unified standard for testing data and standards. Therefore, for the experimental results, it is difficult to have an objective comparison of the advantages and disadvantages of the algorithm. Establishing a common database and testing standard method is a difficult task in the field of athletes'attention state detection.

All authors declare no potential conflict of interest related to this article

AUTHORS' CONTRIBUTIONS: The author has completed the writing of the article or the critical review of its knowledge content. This paper can be used as the final draft of the manuscript. Every author has made an important contribution to this manuscript. Yun Tan: writing and execution. Guoging Zhang: data analysis and surgery.

\section{REFERENCES}

1. Zheng W, Bo W, Liu C, Wang WS. Improved BP neural network algorithm to wind power forecast. Journal of Engineering. 2017;13:940-3.

2. Clark M, Mihalik J, Guskiewicz K. Wooden heads and glass jaws: the long-term effects of recurrent concussion and american football exposure on resting state networks. BJSM. 2017;51(11):A26.3-A27.

3. Song FY, Yuan LU, Yang X, et al. Calculation of infrared transmittances based on BP neural network. Journal of Optoelectronics.laser, 2017;28(6):680-5.

4. Liu T, Yin S. An improved particle swarm optimization algorithm used for BP neural network and multimedia course-ware evaluation. Multimedia Tools \& Applications. 2017;76(9):11961-74.

5. Colzato LS, Nitsche MA, Kibele A. Noninvasive brain stimulation and neural entrainment enhance athletic performance - a review. Journal of Cognitive Enhancement. 2017;1(1):73-9.

6. Masaki H, Maruo Y, Meyer A, Hajcak G. Neural Correlates of choking under pressure: athletes high in sports anxiety monitor errors more when performance is being evaluated. Dev Neuropsychol. 2017;42(2):104-12

7. Przednowek K, Iskra J, Wiktorowicz K, Krzeszowski T, Maszczyk A. Planning Training Loads for the 400 M Hurdles in Three-Month Mesocycles using Artificial Neural Networks. J Hum Kinet. 2017;60:175-89. 